\title{
12. Nachtrag zu unseren Mittheilungen über Versuche mit Röntgenstrahlen ${ }^{1}$ ); von A. Voller und B. Walter.
}

Die Herren A. Winkelmann und R. Straubel haben uns mit Recht darauf aufmerksam gemacht, dass der in unserer Arbeit über Röntgenstrahlen (p. 94) angezogene Werth des Brechungsexponenten des Kupfers für $X$-Strahlen, den diese Beobachter gefunden hatten, einer früheren vorläufigen Mittheilung entstammte, dass sie selbst aber bereits vor unserer Publication in einer Arbeit vom 31. Juli $1896^{2}$ ) auf eine früher unbeachtet gebliebene Fehlerquelle hingewiesen haben, die diesen von uns angezogenen, von unserem eigenen stark abweichenden Werth des Brechungsexponenten beeinflusst habe. Wir bedauern sehr, die spätere Arbeit der Herren Winkelmann und Straubel bei der etwas eilig erfolgten Abfassung unserer Mittheilungen nicht genug beachtet zu haben um so mehr, als das von diesen Beobachtern mitgetheilte spätere Resultat, dass „der Brechungsexponent des Eisens höchstens um 0,0005 von 1 abweicht" sich in guter Uebereinstimmung mit unseren eigenen Ergebnissen befindet, wonach der Brechungsexponent des Kupfers höchstens um $\pm 0,001$ von 1 verschieden ist und auch derjenige des Diamanten und des Aluminiums in den Grenzen $1 \pm 0,0002$ eingeschlossen liegt. Hamburg, Phys. Staatslab., 20. Juni 1897.

1) A. Voller u. B. Walter, Wied. Ann. 61. p. 88. 1897.

2) A. Winkelmann u. R. Straubel, Wied. Ann. 59. p. 324. 1896. (Eingegangen 25. Juni 1897.) 